University of Nebraska - Lincoln

DigitalCommons@University of Nebraska - Lincoln

USDA Wildlife Services - Staff Publications

U.S. Department of Agriculture: Animal and Plant Health Inspection Service

6-25-2007

\title{
Fence-Line Contact Between Wild and Farmed White-Tailed Deer in Michigan: Potential for Disease Transmission
}

\author{
Kurt C. VerCauteren \\ USDA-APHIS-Wildlife Services, kurt.c.vercauteren@usda.gov \\ Michael J. Lavelle \\ USDA/APHIS/WS National Wildlife Research Center, michael.j.lavelle@aphis.usda.gov \\ Nathan W. Seward \\ United States Department of Agriculture, Animal and Plant Health Inspection Service, Wildlife Services, \\ National Wildlife Research Center \\ Justin W. Fischer \\ USDA/APHIS/WS National Wildlife Research Center, Justin.w.fischer@aphis.usda.gov \\ Gregory E. Phillips \\ United States Department of Agriculture, Animal and Plant Health Inspection Service, Wildlife Services, \\ National Wildlife Research Center
}

Follow this and additional works at: https://digitalcommons.unl.edu/icwdm_usdanwrc

Part of the Environmental Sciences Commons

VerCauteren, Kurt C.; Lavelle, Michael J.; Seward, Nathan W.; Fischer, Justin W.; and Phillips, Gregory E., "Fence-Line Contact Between Wild and Farmed White-Tailed Deer in Michigan: Potential for Disease Transmission" (2007). USDA Wildlife Services - Staff Publications. 721.

https://digitalcommons.unl.edu/icwdm_usdanwrc/721

This Article is brought to you for free and open access by the U.S. Department of Agriculture: Animal and Plant Health Inspection Service at DigitalCommons@University of Nebraska - Lincoln. It has been accepted for inclusion in USDA Wildlife Services - Staff Publications by an authorized administrator of DigitalCommons@University of Nebraska - Lincoln. 


\title{
Fence-Line Contact Between Wild and Farmed White- Tailed Deer in Michigan: Potential for Disease Transmission
}

\author{
KURT C. VERCAUTEREN, ${ }^{\mathbf{1}}$ United States Department of Agriculture, Animal and Plant Health Inspection Service, Wildlife Services, National Wildife \\ Research Center, 4101 LaPorte Avenue, Fort Collins, CO 80521, USA \\ MICHAEL J. LAVELLE, United States Department of Agriculture, Animal and Plant Health Inspection Service, Wildife Services, National Wildlife \\ Research Center, 4101 LaPorte Avenue, Fort Collins, CO 80521, USA \\ NATHAN W. SEWARD, United States Department of Agriculture, Animal and Plant Health Inspection Service, Wildife Services, National Wildlife \\ Research Center, 4101 LaPorte Avenue, Fort Collins, CO 80521, USA \\ JUSTIN W. FISCHER, United States Department of Agriculture, Animal and Plant Health Inspection Service, Wildlife Services, National Wildlife \\ Research Center, 4101 LaPorte Avenue, Fort Collins, CO 80521, USA \\ GREGORY E. PHILLIPS, United States Department of Agriculture, Animal and Plant Health Inspection Service, Wildlife Services, National Wildife \\ Research Center, 4101 LaPorte Avenue, Fort Collins, CO 80521, USA
}

\begin{abstract}
Interactions between wild and farmed white-tailed deer (Odocoileus virginianus) along perimeter fences may play a role in the transmission of diseases like bovine tuberculosis and chronic wasting disease. However, no study has evaluated direct contact between wild and farmed deer through fences. We used animal-activated cameras to estimate rates of interaction between wild and farmed deer at 6 high-fenced commercial white-tailed deer farms in Michigan, USA, during October 2003 to January 2005. We recorded only 2 direct, naso-oral contacts between wild and farmed deer during $>77,000$ hours of camera monitoring. We documented little direct contact between wild and captive deer through fences and, therefore, believe there is limited potential for direct transmission of diseases. However, we suspect our results are conservative and do not rule out the risks of direct or indirect disease transmission into or out of deer farms. Our findings will be of use to federal and state agencies responsible for regulating deer farms as well as managers of such facilities. (JOURNAL OF WILDLIFE MANAGEMENT 71(5):1603-1606; 2007)
\end{abstract}

DOI: $10.2193 / 2006-179$

KEY WORDS bovine tuberculosis, cameras, cervid, CWD, disease, fence, game farm, Michigan, Odocoileus virginianus, transmission.

Private farming of cervids behind high fences has grown in Michigan, USA, and throughout North America over the past 30 years (Hunter 1996, Coon et al. 2002) and has become an important conservation issue (Demarais et al. 2002). Bovine tuberculosis (TB) and chronic wasting disease (CWD) in wild and farmed cervids have resource management agencies reexamining the governing of private ownership and management of wildlife. Bovine TB and CWD have potential to severely affect farmed and wild cervid populations (Miller and Thorne 1993, Hunter 1996, Williams 2005), and bovine TB is a threat to the cattle industry (O'Brien et al. 2006).

Over the past century, a concerted effort has been made to eradicate bovine TB from cattle in the United States, and frequency of outbreaks has declined. Bovine TB is established in wild white-tailed deer (Odocoileus virginianus) in northeastern lower Michigan, and they have been implicated for continually infecting cattle herds. Bovine TB is transmitted between animals through aerosol, saliva, and nasal secretions (Morris et al. 1994, Sauter and Morris 1995, Palmer et al. 1999, Clifton-Hadley et al. 2001). Artificial feed sites in northeastern lower Michigan (as described in Palmer et al. 2004) may exacerbate the situation by concentrating deer, thus increasing potential for infected individuals to interact with others and contaminate feed

${ }^{1}$ E-mail: Kurt.C.VerCauteren@aphis.usda.gov
(Schmitt et al. 1997; Palmer et al. 1999, 2001, 2004). Clusters of high bovine TB prevalence concentrated around artificial feed and baiting sites demonstrate the increased risk for spreading the disease (O'Brien et al. 2006). The United States Department of Agriculture (1996) stated that farmed white-tailed deer in this region may be at a higher risk than other domestic livestock for contracting bovine TB from wild white-tailed deer through social contact at fences. A survey of privately owned cervid farms in Michigan revealed that perimeter fences at most of these facilities $(94.4 \% ; 118 / 125)$ could not impede direct contact between wild and farmed cervids (O'Brien et al. 2005). Further, fence-line contact between wild mule deer (Odocoileus hemionus) and farmed elk (Cervus elaphus) was implicated in an outbreak of bovine TB in Montana, USA (Rhyan et al. 1995, U.S. Department of Agriculture 1996).

Early outbreaks of CWD in wild cervids occurred adjacent to high-fenced research facilities where CWD was present (Miller and Wild 2004), and fence-line contact was implicated (Williams et al. 2000). Recently, outbreaks of CWD in farmed deer in Nebraska, USA, and Wisconsin, USA, have been associated with CWD in wild deer in adjacent areas. More importantly, at least in Nebraska, CWD prevalence rates in wild deer decreased as the sampling distance from the CWD-positive farms increased (J. Boner, University of Nebraska, personal communication). 
Table 1. Camera monitoring effort, number of times wild and farmed white-tailed deer were documented with cameras along fences, direct-contact rates, and wild-deer visitation rates along the fences of 6 deer farms in Michigan, USA, October 2003 to January 2005.

\begin{tabular}{ccccrc}
\hline Site & $\begin{array}{c}\text { Camera monitoring } \\
\text { effort (1,000 hr) }\end{array}$ & Farmed deer & Wild deer & Direct contacts & $\begin{array}{c}\text { Direct contacts/ } \\
\mathbf{1 , 0 0 0} \mathbf{h r}\end{array}$ \\
\hline 1 & 16.04 & 254 & 34 & 0 & 0.00 \\
visitations/1,000 hr
\end{tabular}

Miller and Thorne (1993) reported that the potential for transmission exists between farmed and wild cervids via direct contact along fence lines, ingress or egress of infected animals, and environmental contamination.

Previous research on farmed-cervid fencing has focused on either containing or excluding animals; direct contact between farmed and wild cervids along fences has not been quantified. Our objectives were 1) to document behaviors and contacts that occurred between farmed and wild whitetailed deer through game-farm fences, and 2) to deduce the potential for direct and indirect disease transmission between wild and farmed deer.

\section{STUDY AREA}

We worked on 6 privately owned cervid farms in northeastern lower Michigan (locations and ownership not provided per United States Department of Agriculture policy). Deer densities on the farms averaged 118 deer $/ \mathrm{km}^{2}$ $(\mathrm{SE}=0.23$, range $=39-395)$. The farms varied in size $(\bar{x}=$ $181 \mathrm{ha}, \mathrm{SE}=63.5$, range $=19-464)$ and were surrounded by habitat that sustained wild deer (density $=19-23$ deer $/ \mathrm{km}^{2}$; Schmitt et al. 1997). Wild elk also inhabited the area (0.8 $\mathrm{elk} / \mathrm{km}^{2}$; Bender et al. 1999). All sites employed a single 3$\mathrm{m}$ high woven-wire fence to separate wild and farmed cervids. Elevations averaged $314 \mathrm{~m}$ with the surrounding vegetation characterized by mixed deciduous and coniferous forest, forage crops, and grassland.

\section{METHODS}

\section{Data Collection}

We collected video of cervid presence, behavior, and direct physical contact between wild and farmed deer along fence lines from October 2003 through January 2005 using animal-activated camera systems (Reconyx Silent Image ${ }^{\mathrm{TM}}$, La Crosse, WI; Stumpcam ${ }^{\mathrm{TM}}$ model 9951, Stumpcam, Inc., Tyler, TX; and TrailMaster ${ }^{\circledR} 700 v$, Goodson and Associates, Inc., Lenexa, KS). We placed cameras nonrandomly by putting them in areas we believed to have high potential for cervid interaction based on occurrence of tracks on both sides of fences. We mounted cameras on brackets secured to fence posts and aimed down fence lines. We positioned cameras so approximately $67 \%$ of the field of view (FOV, where $\mathrm{FOV}=14 \mathrm{~m}$ at $20 \mathrm{~m}$ from camera) was outside the fence and $33 \%$ of FOV-captured footage on the inside. Stumpcams and TrailMasters captured video using a Sony ${ }^{\circledR}$
Handycam DCR-TRV350 camcorder (Sony Corporation, Tokyo, Japan). The Silent Image digital cameras were selfcontained and capable of recording video-like imagery. We programmed all cameras to record for 2 minutes after being activated (recording interval) and then to turn off for 2 minutes before reactivation could occur.

We employed 3 cameras at each site and relocated cameras as farmed cervids were rotated among internal enclosures. We collected videotapes and compact flash cards every 2 weeks. For each recording interval, we documented date and time of activation, whether footage was useable (i.e., animals viewed clearly), species, behavior, and number of individuals viewed on both sides of the fence.

\section{Data Analyses}

We defined camera monitoring effort as the summation of time within and among all cameras per site that were functional and available to record animal presence. We scaled observed counts of direct contacts and deer presence by camera monitoring effort so comparisons would be consistent (per 1,000 hr of camera monitoring time). We counted direct animal-to-animal contacts and calculated contact rates by dividing the number of contacts by camera monitoring effort within and among sites. Contact rates were applicable to the FOV at a camera location and can not be confidently extrapolated to full fence-line perimeters. As wild deer visitation rates dictate the potential for interaction and associated disease transmission, we also calculated sitespecific visitation rates in FOV of cameras by wild deer to index potential for direct and indirect disease transmission.

\section{RESULTS}

Camera monitoring effort ranged from 11,530 hours to 17,215 hours for 5 of 6 sites and 4,322 hours for Site 6 (total $\mathrm{hr}$ of monitoring $=77,165$; Table 1 ). Lower camera monitoring effort occurred at Site 6 because it changed ownership, and we subsequently lost access. Cameras recorded occasions of wild deer presence (range $=27-193$ / site) and farmed deer presence (range $=171-928 /$ site). We recorded only 2 direct contacts between wild and farmed deer, 1 at Site 3 and 1 at Site 5. Subsequently, contact rates per 1,000 hours of monitoring at Sites 3 and 5 were 0.08 and 0.09 , respectively, and 0.03 overall.

During 77,165 hours of monitoring, we counted 439 wild deer along fence lines, representing an overall visitation rate of 5.69 deer per 1,000 hours. This corresponds to $\leq 0.96$ 
occasions/week (168 hr) of opportunity for contacts between wild and farmed deer within areas monitored by cameras across all sites. Of the 439 wild deer documented in the FOV, 28\% were feeding along fences, and most others were simply traveling along them. Site-specific wild deer visitation rates ranged from 2.12 to 11.21 deer per 1,000 hours (Table 1).

Two farms contained elk, and our cameras documented their presence along fence lines on several occasions (11 occasions at Site 1; 97 occasions at Site 4). Though wild elk were present in much of the study area, we did not document their activity on any cameras. Thus, we recorded no contacts between wild elk and farmed deer or elk. Additionally, we recorded no contacts between wild deer and farmed elk.

\section{DISCUSSION}

Our rate calculations for wild deer visitation along fences represent potential for direct and indirect interaction to occur between wild and farmed deer. We found a maximum site-specific visitation rate of 11 wild deer per 1,000 hours and documented just 2 direct contacts. Schauber et al. (2007) quantified contact rates among wild white-tailed deer. They documented that deer from different social groups came into contact $\leq 22.1$ times less often than deer from the same social group. Because wild and farmed deer are not members of the same social groups and because the only space they share is along fences, the Schauber et al. (2006) data suggest that little direct contact would occur between them. Regardless, because disease agents like those associated with bovine TB and CWD are persistent in the environment, the levels of activity we present, for the small percentage of fence perimeters we monitored, do demonstrate potential for indirect disease transmission.

Our estimates of direct contact and visitation rates are likely conservative. Though we attempted to randomly sample from the population of privately owned deer farms in northeastern lower Michigan, not all farm operators were willing to participate in the study. Therefore, our conclusions might not represent the overall population of deer farms in the region. Contact and visitation rates could be higher or lower elsewhere.

\section{MANAGEMENT IMPLICATIONS}

Double fencing (i.e., 2 parallel $2.4-\mathrm{m}$ or higher fences situated 2-3 $\mathrm{m}$ apart) of deer farms, as is required by some regulatory agencies (Demarais et al. 2002) and proposed by others, would serve to reduce the potential for both direct and indirect disease transmission. As farmed deer do escape relatively often (O'Brien et al. 2005, Rolley 2005), another likely mode of disease transmission may be through the ingress and egress of deer from deer farms. Disease can be transmitted through fences in a variety of ways (e.g., fence line contact, breaches of unmaintained fences and gates, and deer farm operator movements of diseased deer), so operators and wildlife managers need to remain vigilant.

\section{ACKNOWLEDGMENTS}

We thank owners of cervid farms for granting access to their properties. We also thank R. Otto and J. Duquette for assistance with fieldwork. We dedicate this study to R. Pooler, who passed away before its completion. All procedures were approved by the United States Department of Agriculture, Animal and Plant Health Inspection Service, Wildlife Service, National Wildlife Research Center Institutional Animal Care and Use Committee. Reference to trade names does not imply United States government endorsement of commercial products or exclusion of similar products.

\section{LITERATURE CITED}

Bender, L. C., D. E. Beyer, and J. B. Haufler. 1999. Effects of shortduration, high-intensity hunting on elk wariness in Michigan. Wildlife Society Bulletin 27:441-445.

Clifton-Hadley, R. S., C. M. Sauter-Louis, I. W. Lugton, R. Jackson, P. A Durr, and J. W. Wilesmith. 2001. Mycobacterial diseases. Pages 340-361 in E. S. Williams and I. K. Barker, editors. Infectious diseases of wild animals. Iowa State University Press, Ames, USA.

Coon, T. G., H. Campa, A. B. Felix, R. B. Peyton, S. R. Winterstein, F. Lupi, M. Schulz, and J. Sikarskie. 2002. Farming captive cervids: a review of social, economic and ecological opportunities and risks in Michigan and North America. Transactions of the North American Wildlife and Natural Resources Conference 67:251-268.

Demarais, S., R. W. DeYoung, L. J. Lyon, E. S. Williams, S. J. Williamson, and G. J. Wolfe. 2002. Biological and social issues related to confinement of wild ungulates. The Wildlife Society Technical Review 02-3, Bethesda, Maryland, USA.

Hunter, D. L. 1996. Tuberculosis in free-ranging, semi free-ranging and captive cervids. Revue Scientifique et Technique Office International des Epizooties 15:171-181.

Miller, M. W., and E. T. Thorne. 1993. Captive cervids as potential sources of disease for North America's wild cervid populations: avenues, implications and preventive management. Transactions of the North American Wildlife and Natural Resources Conference 58:460-467.

Miller, M. W., and M. A. Wild. 2004. Epidemiology of chronic wasting disease in captive white-tailed and mule deer. Journal of Wildlife Disease 40:320-327.

Morris, R. S., D. U. Pfeiffer, and R. Jackson. 1994. The epidemiology of Mycobacterium bovis infections. Veterinary Microbiology 40:153-177.

O'Brien, D., P. Bernardi, S. Dubay, S. Mayhew, W. Moritz, and D. Purol. 2005. A risk-based audit of the captive/privately-owned cervid industry in Michigan. Michigan Department of Natural Resources Report Series Issue 1, Lansing, USA.

O’Brien, D. J., S. M. Schmitt, S. D. Fitzgerald, D. E. Berry, and G. J. Hickling. 2006. Managing The wildlife reservoir of Mycobacterium bovis: the Michigan, USA, experience Veterinary Microbiology 40:313-323.

Palmer, M. V., W. R. Waters, and D. L. Whipple. 2004. Shared feed as a means of deer-to-deer transmission of Mycobacterium bovis. Journal of Wildlife Diseases 40:87-91.

Palmer, M. V., D. L. Whipple, and S. C. Olsen. 1999. Development of a model of natural infection with Mycobacterium bovis in white-tailed deer. Journal of Wildlife Diseases 35:450-457.

Palmer, M. V., D. L. Whipple, and R. Waters. 2001. Experimental deerto-deer transmission of Mycobacterium bovis. American Journal of Veterinary Research 62:692-696.

Rhyan, J., K. Aune, B. Hood, R. Clarke, J. Payeur, J. Jarnagin, and L. Stackhouse. 1995. Bovine tuberculosis in free-ranging mule deer (Odocoileus hemionus) from Montana. Journal of Wildlife Diseases 31: 432-435.

Rolley, R. E. 2005. Controlling chronic wasting disease in Wisconsin: a progress report and look toward the future. Wisconsin Department of Natural Resources, Madison, USA.

Sauter, C. M., and R. S. Morris. 1995. Behavioural studies on the potential for direct transmission of tuberculosis from feral ferrets (Mustela furo) and 
possums (Trichosurus vulpecula) to farmed livestock. New Zealand Veterinary Journal 43:294-300.

Schauber, E. M., D. J. Storm, and C. K. Nielsen. 2007. Effects of joint space use and group membership on contact rates among white-tailed deer. Journal of Wildlife Management 71:155-163.

Schmitt, S. M., S. D. Fitzgerald, T. M. Cooley, C. S. Bruning-Fann, L. Sullivan, D. Barry, T. Carlson, R. B. Minnis, J. B. Payeur, and J. Sikarskie. 1997. Bovine tuberculosis in free-ranging white-tailed deer from Michigan. Journal of Wildlife Diseases 33:749-758.

U.S. Department of Agriculture. 1996. Assessing the risks associated with
M. Bovis in Michigan free-ranging white-tailed deer. Centers for Epidemiology and Animal Health, Fort Collins, Colorado, USA.

Williams, E. S. 2005. Chronic wasting disease. Veterinary Pathology 42: 530-549.

Williams, E. S., W. Cook, H. Edwards, S. Smith, and T. R. Kreeger. 2000. Chronic wasting disease in elk (Cervus elaphus nelsoni) held in a CWD endemic facility. Abstract. Proceedings of the annual meeting of the Wildlife Disease Association, 4-8 June 2000, Jackson,Wyoming, USA.

Associate Editor: McCorquodale. 